\title{
RELIABLE IDENTIFICATION AND SELECTION OF CRITICAL INNOVATION DESIGN TASKS FOR PROCESS INTENSIFICATION IN PROCESS ENGINEERING
}

\author{
P. Livotov ${ }^{\otimes}$, Mas'udah and A. P. Chandra Sekaran \\ Offenburg University of Applied Sciences, Germany \\ $\triangle$ pavel.livotov@hs-offenburg.de
}

\begin{abstract}
Sustainable design of equipment for process intensification requires a comprehensive and correct identification of relevant stakeholder requirements, design problems and tasks crucial for innovation success. Combining the principles of the Quality Function Deployment with the Importance-Satisfaction Analysis and Contradiction Analysis of requirements gives an opportunity to define a proper process innovation strategy more reliably and to develop an optimal process intensification technology with less secondary engineering and ecological problems.
\end{abstract}

Keywords: design methods, eco-innovation, quality function deployment (QFD), process engineering

\section{Introduction}

Sustainable innovation and design can be characterised as a sequence of decisions concerning various requirements and multiple solutions (Masui, 2001; Azzaro-Pantel, 2015; Tyl et al., 2016). Current process design practice in the field of Process Engineering is based on the Process Intensification approach (Boodhoo and Harvey, 2013) and tends to focus on improvements based on the stakeholder requirements without taking into consideration the relationship between importance and fulfilment level of requirements in the existing processes and without anticipation of cause-effect chains and negative side effects from the technical and environmental point of view. Therefore, there is a need to develop a process innovation design method for process intensification under consideration of processing technologies, applied equipment with its advantages and drawbacks, material and energy flows. The idea of using the integration of Quality Function Deployment (QFD) with Importance-Satisfaction Analysis (ISA) has been proposed for sustainable innovation in Process Engineering in (Mas'udah et al., 2019). The method helps to identify innovation tasks as well as potential engineering and ecological contradictions. It offers a systematic way to match customer expectations with the technical requirements in the early stages of design. The Process Mapping approach (Casner and Livotov, 2017) is applied in this method to comprehensively identify problems and innovation tasks, formulated as solution-neutral process intensification requirements. The Importance-Satisfaction Analysis (Bettencourt and Ulwick, 2008; Casner and Livotov, 2017) results in more objective ranking of requirements and leads to a more reliable identification of process intensification problems with higher priority for innovation success. The House of Quality (HoQ) as the core part of the QFD method, conceptualised by Akao (Akao, 1986; Chan and Wu, 2002; Sisasamy et al., 2016), helps to document and visualize the stakeholder requirements (SRs), technical functions (later termed as technical 
requirements - TRs), the positive and negative interactions between technical and stakeholder requirements. The proposed method for identification of critical innovation tasks is using the following metrics: importance, satisfaction and ranking of the stakeholder requirements, relevance of technical requirements and estimated synergy and contradiction indexes of requirements. The paper presents a case study of innovation task definition for process intensification in pharmaceutical tablet manufacturing. It focuses on 33 identified requirements of stakeholders (primarily, the manufacturing companies, their customers, and finally the consumers) and illustrates the identification of the cause-effect chains and potential secondary problems for different innovation scenarios.

\section{Methodology}

The integration of QFD with ISA includes five phases of building the House of Quality (HoQ) and is illustrated in the Figure 1. The phase 1 contains the creation correlation matrix of technical requirements (TRs) or functions of process equipment in each technological process step. In the phase 2 the correlation matrix of the solution-neutral stakeholder requirements (SRs) has to be defined independently from the existing technological process. Both the TRs and SRs correlation matrices are indicated with the correlation coefficients $\mathrm{C}_{\mathrm{TR}}$ and $\mathrm{C}_{\mathrm{SR}}$ equal " -1 " for a possible negative correlation (contradiction), equal " +1 " for a possible synergy impact, and equal " 0 " - in case of a neutral or unknown relationship between two requirements. Based on these correlation matrices, Synergy ( $\left.i_{s}\right)$ and Contradiction $\left(i_{c}\right)$ Indexes can be calculated for SRs and TRs respectively as a number of positive $(+1)$ and a number of negative correlations (-1):

$$
\begin{aligned}
& \text { Synergy Index: } \quad i_{s}=\sum_{j=1}^{j=m} C_{x j}(\mathrm{C}=+1) \\
& \text { Contradiction Index: } i_{c}=\sum_{j=1}^{j=m} C_{x j}(\mathrm{C}=-1)
\end{aligned}
$$

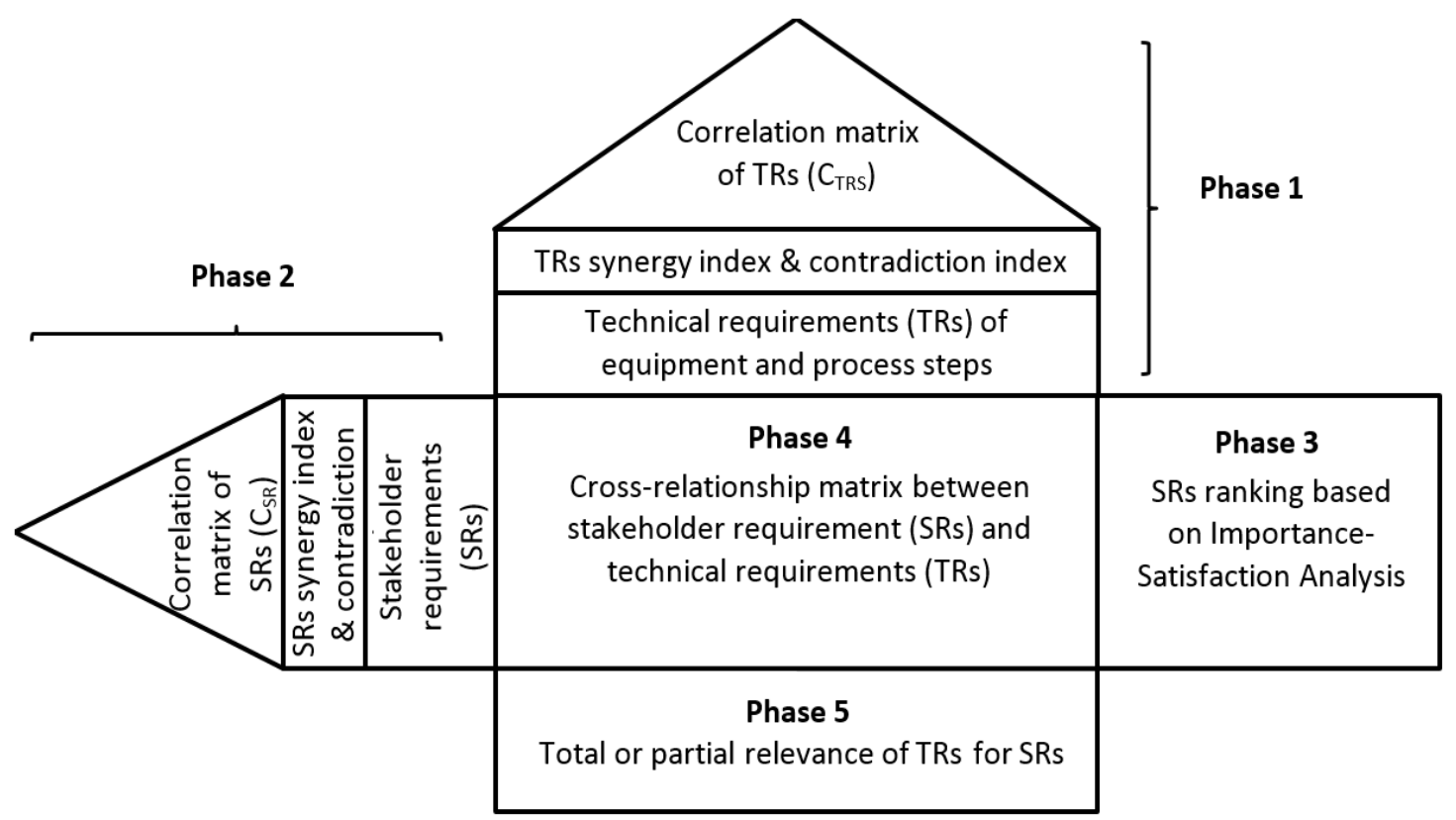

Figure 1. HoQ for requirements ranking in process engineering (Mas'udah et al., 2019)

In the phase 3 the importance of each stakeholder requirement and its current performance (defined as satisfaction with its fulfilment in the existing process) have to be evaluated from a stakeholders' point of view. The assignment of importance and satisfaction uses a scale from $0 \%$ to $100 \%$ (100\% - very high level of importance or performance, $80 \%$ - high, $60 \%$ - middle, $40 \%$ - low, $20 \%$ - very low 
importance or performance). Obtained importance and satisfaction mean values allow one to calculate the ranking of each stakeholder requirement using the following equation (Livotov, 2008):

$$
\operatorname{Rank}_{S R x}=\frac{\left\{I_{S R x}+a I_{S R x}\left(I_{S R x}-S_{S R x}\right)\left(1-S_{S R x}\right)\right\}}{\sum_{x=1}^{x=m}\left\{I_{S R x}+a I_{S R x}\left(I_{S R x}-S_{S R x}\right)\right\}}
$$

where:

$$
\begin{array}{ll}
\text { Rank }_{\mathrm{SRx}} & - \text { ranking of stakeholder requirement } \mathrm{x}(\mathrm{SRx}), \% ; \\
\mathrm{I}_{\mathrm{SRx}} & - \text { importance level of SRx, } 0 \ldots 100 \% ; \\
\mathrm{S}_{\mathrm{SRx}} & - \text { satisfaction level of SRx, } 0 \ldots 100 \% ; \\
\mathrm{m} & - \text { total number of stakeholder requirements; } \\
\mathrm{a} & - \text { adjustment coefficient; a=1 recommended for PE. }
\end{array}
$$

The phase 4 comprises the cross-relationship analysis of the stakeholder requirements SRs and technical requirements TRs. In this stage, the assignment uses binary classification. The YES-option (impact factor $F$ $=1$ or $\mathrm{F}=-1$ ) is applied if a SR is affected positively or negatively by the corresponding TR. Whilst the NO-option (impact factor $\mathrm{F}=0$ ) is indicated if a TR shows neither improving nor worsening effect on $\mathrm{SR}$. Finally, the phase 5 includes the summary of the total, positive or negative relevance of each TR for all stakeholder requirements SRs. Additionally, the partial relevance of each TR for specific SRs group, for example, the partial relevance of each TR to the eco-requirements, can be estimated in this step. The calculation of the total relevance of any technical requirement TRx for all stakeholder requirements SRs is based on the correlations between SRs and TRs in accordance to the following equation:

$$
\operatorname{Rel}_{T R x \rightarrow S R s}=\sum_{j=1}^{j=m}\left(\operatorname{Rank}_{S R j} \times\left|F_{x j}\right|\right)
$$

where:

$$
\begin{array}{ll}
\text { Rel }_{\mathrm{TRx} \rightarrow \mathrm{SRs}} & - \text { total relevance of a technical requirement } \mathrm{x}(\mathrm{TRx}) \text { for all SRs; } \\
\text { Rank }_{\mathrm{SRj}} & - \text { ranking of a stakeholder requirement } \mathrm{j}(\mathrm{SRj}), \% ; \\
\mathrm{F}_{\mathrm{xj}} & - \text { impact factor of a TRx to a stakeholder requirement SRj: Fxj=1 if TR is improving } \\
& \text { SR, or Fxj=-1 if TR is worsening SR (YES-option); Fxj=0 if TRs have not influence } \\
& \text { on SRs (NO-option) - see phase 4; } \\
\mathrm{m} & - \text { total number of stakeholder requirements SRs. }
\end{array}
$$

The following metrics can be taken into account for selection of sustainable innovation design tasks:

- Importance of stakeholder requirements SRs. The innovation activities can be focused on the requirements with higher importance independently of their satisfaction level.

- Ranking of stakeholder requirements SRs based on their importance and satisfaction values. In accordance with the Importance-Satisfaction Analysis, the requirements with higher importance and lower performance have a higher ranking in a process innovation strategy.

- Total relevance of technical requirements TRs to all stakeholder needs SRs. The relevance values of TRs help identify which technical functions enable to fulfil the selected stakeholder requirements.

- Synergy and Contradiction Indexes of requirements. Synergy and Contradiction Indexes can be also used in optimization algorithms for selection of the process intensification and innovation strategies.

- Number of potential secondary problems resulting from enhancement of selected technical or stakeholder requirements with the corresponding cause-effect chains.

These elements are essential for the decision making for process intensification design in the early stages of development. As illustrated in Figure 2, a reliable selection of the innovation tasks should be based on several complementary metrics such as importance of solution-neutral stakeholder requirements, importance-satisfaction ranking of stakeholder requirements, relevance of the corresponding technical 
functions, contradiction indexes of stakeholder requirements and technical functions. From this analysis, the top 5-10 innovation design tasks can be identified for the design phase of the process intensification.

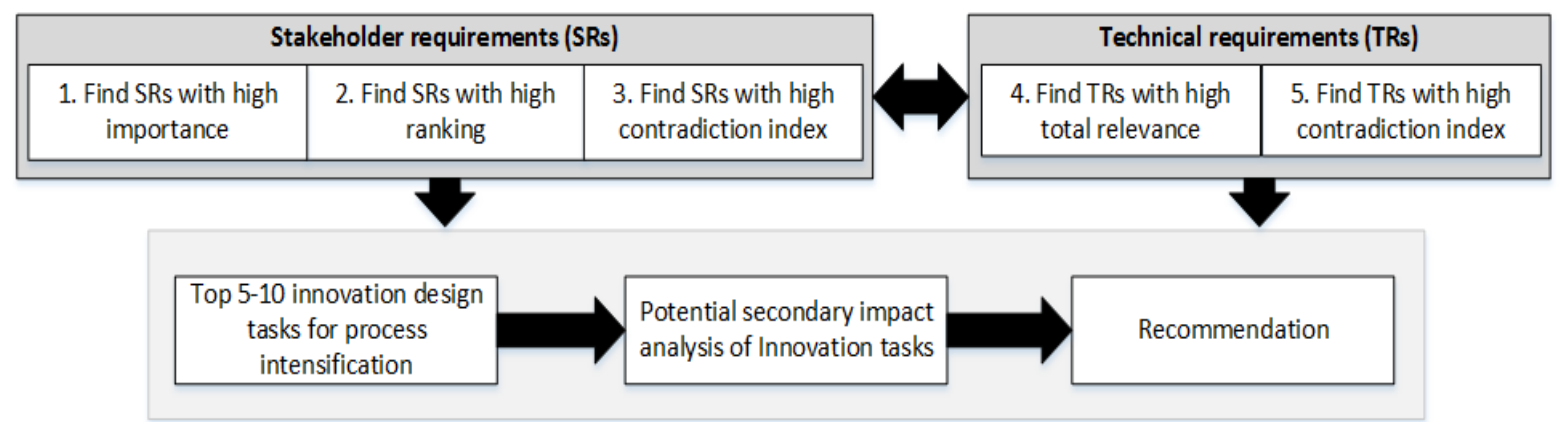

Figure 2. Identification and selection of innovation design tasks using multicriteria approach

Additionally, the cause-effect relationship (Dobrusskin, 2016) of innovation tasks can be examined using the correlation matrices of SRs and TRs with the purpose to identify the contradictions between innovation goals and to estimate possible negative secondary impact of the innovation tasks. Overcoming of the contradictions between the requirements often delivers new opportunities for the future-oriented technological progress (Pfeuffer and Scherb, 2016).

\section{Case study}

The described approach for identification of innovation design tasks is illustrated with an industrial case study for process intensification dealing with pharmaceutical tablet manufacturing. The process steps and process equipment are presented in Figure 3 and Table 1 respectively. Application of the Process Mapping technique and Function Analysis has resulted in the identification of 33 major solution-neutral stakeholder requirements and 19 technical requirements, i.e. technical functions of the equipment.

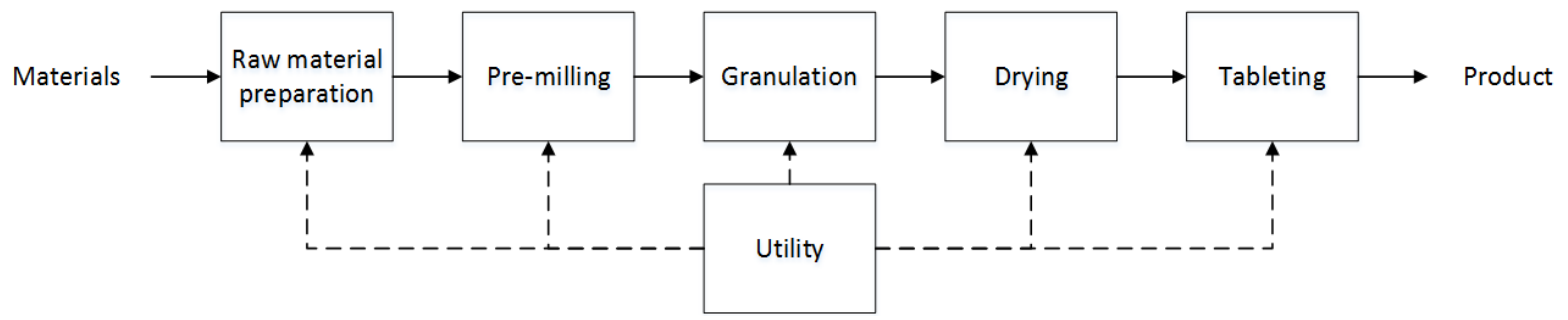

Figure 3. Process steps of tablet production in pharmaceutical manufacturing

Table 1. Unit process equipment of pharmaceutical tablet manufacturing

\begin{tabular}{ll}
\hline \multicolumn{1}{c}{ Process Steps } & \multicolumn{1}{c}{ Equipment } \\
\hline 1. Raw material preparation & (1.1) Excavators and belt conveyers; (1.2) Containers; (1.3) Scales; \\
& (1.4) Sieve and belt conveyers; (1.5) Bins \\
2. Pre-milling & (2.1) Pre-blender; (2.2) Dissolution mixer \\
3. Granulation & (3.1) Kneader; (3.2) Slurry pump \\
4. Drying & (4.1) Dryer; (4.2) Sieve; (4.3) Mixer \\
5. Tabletting & (5.1) Tableting unit \\
6. Utility & (6.1) Dust collector; (6.2) Water depuration system \\
\hline
\end{tabular}

The stakeholder requirements can be assigned to the technological (T) group, such as "avoid disintegration of tablets", or environmental (E) group, such as for example "reduce dust generation", or "reduce water consumption". The identified correlations between SRs and TRs as well as the results of the ImportanceSatisfaction evaluation are presented in the extended House of Quality in Figure 4. Interestingly, that at the beginning of the analysis the dust generation was seen as one of the core problems the tablets manufacturer wanted to solve. 


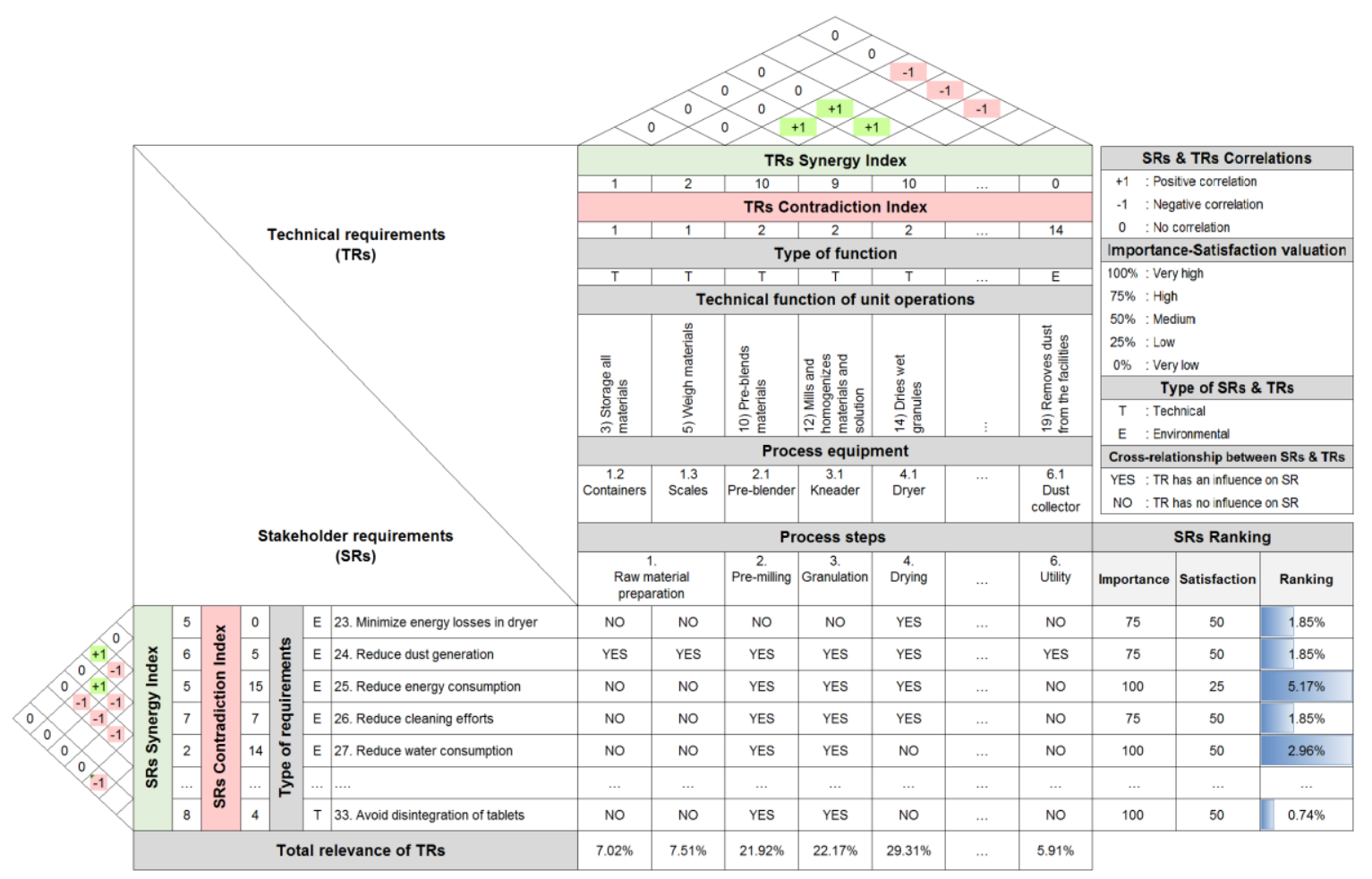

Figure 4. Visualisation of the process mapping and evaluation results in a case study (fragment)

\section{Results and discussion}

\subsection{Innovation design tasks}

As shown in Figure 4, the stakeholder requirements are valued by their importance, satisfaction and ranking metrics. The indicated correlations between stakeholder requirements and between technical requirements allows to calculate the corresponding contradiction and synergy indexes of the SRs and TRs respectively. And finally, the estimated YES/NO relationship between SRs and TRs allows to calculate the total relevance of each technical requirement TR. Nevertheless, different criteria can be used separately for identification of the innovation tasks as presented in the Figures $5-8$ below.

\subsubsection{Stakeholder requirements with high importance}

The importance and satisfaction of each individual stakeholder requirement were rated by the experts from the pharmaceutical industry. Thus, the high importance requirements represent primary concerns and priority of stakeholders, independently of technological solutions used in the existing manufacturing process.

Figure 5 compares the top 10 SRs with highest importance in total with top 10 environmental and top 10 technological stakeholder requirements with highest importance.

\begin{tabular}{|c|c|c|}
\hline Top 10 SRs with high importance & Top 10 environmental SRs with high importance & Top 10 technological SRs with high importance \\
\hline 2. Control raw materials quality & 27. Reduce water consumption & 31. Avoid poor tablet pressing \\
\hline 8. Avoid weighing errors of.. & 25. Reduce energy consumption & 9. Avoid cross contamination of raw... \\
\hline 9. Avoid cross contamination of raw... & 24. Reduce dust generation & 8. Avoid weighing errors of.. \\
\hline 25. Reduce energy consumption $100 \%$ & 23. Minimize energy losses in... & 2. Control raw material quality \\
\hline 27. Reduce water consumption $100 \%$ & 21. Minimize air pollution in drying.. $75 \%$ & 7. Minimize bulking of powder due... \\
\hline 31. Avoid poor tablet pressing $100 \%$ & 11. Control speed of sieving machine $50 \%$ & 5. Avoid material labelling mistakes \\
\hline 21. Minimize air pollution in drying... $75 \%$ & 6. Avoid high pressure in weighing.. $50 \%$ & 30. Avoid friable tablets \\
\hline 22. Reduce membrane fouling in... $75 \%$ & 4. Decrease safety risks in warehouse $50 \%$ & 29. Avoid non homogenized.. $75 \%$ \\
\hline 23. Minimize energy losses in.. $75 \%$ & 20. Reduce noise level in drying.. $50 \%$ & 28. Avoid sticky granulate $75 \%$ \\
\hline 24. Reduce dust generation $75 \%$ & 26. Reduce cleaning efforts $=50 \%$ & 22. Reduce membrane fouling in... $75 \%$ \\
\hline
\end{tabular}

Figure 5. Top 10 stakeholder requirements with high importance 


\subsubsection{Stakeholder requirements with high ranking}

The stakeholder requirements with higher importance and lower satisfaction (or lower performance) have a higher ranking in a process innovation strategy. In the presented pharmaceutical case study the higher ranking of SRs has been estimated for reduction of energy and water consumption, and for improvement of the product quality and accuracy of process operations. Figure 6 presents top $10 \mathrm{SRs}$ and compares environmental and technological requirements with highest ranking.

\begin{tabular}{|c|c|c|c|c|}
\hline Top 10 SRs with high ra & anking & Top 10 environmental SRs with $\mathrm{hi}$ & high ranking & Top 10 technological SRs with high ranking \\
\hline 25. Reduce energy consumption & $5.17 \%$ & 25. Reduce energy consumption & $5.17 \%$ & 28. Avoid sticky granulate \\
\hline 27. Reduce water consumption & $2.96 \%$ & 27. Reduce water consumption & $2.96 \%$ & 22. Reduce membrane fouling in dryer \\
\hline 29. Avoid non homogenize blending.. & - $1.85 \%$ & 26. Reduce cleaning efforts & - $1.85 \%$ & 30. Avoid friable tablets \\
\hline 23. Minimize energy losses in drying & - $1.85 \%$ & 24. Reduce dust generation & - $1.85 \%$ & 29. Avoid non homogenized.. \\
\hline 21. Minimize air pollution in drying & - $1.85 \%$ & 23. Minimize energy losses in drying & - $1.85 \%$ & 2. Control raw material quality $1.23 \%$ \\
\hline 26. Reduce cleaning efforts & - $1.85 \%$ & 21. Minimize air pollution in drying & - $1.85 \%$ & 8. Avoid weighing errors of.. \\
\hline 24. Reduce dust generation & - $1.85 \%$ & 20. Reduce noise level in dryer & - $1.85 \%$ & 31. Avoid poor tablet pressing \\
\hline 22. Reduce membrane fouling in dryer & - $1.85 \%$ & 11. Control speed of sieving machine I & $0.37 \%$ & 9. Avoid cross contamination of raw.. \\
\hline 20. Reduce noise level in dryer & - $1.85 \%$ & 6. Avoid high pressure in weighing...I & $0.37 \%$ & 5. Avoid material labelling mistakes $0.74 \%$ \\
\hline 28. Avoid sticky granulate & - $1.85 \%$ & 4. Decrease safety risks in warehouse $\quad$ & $0.37 \%$ & 18. Reduce granulation time $=0.74 \%$ \\
\hline
\end{tabular}

Figure 6. Top 10 stakeholder requirements with high ranking

\subsubsection{Stakeholder requirements with high contradiction index}

Focusing on the stakeholder requirements with high contradiction index can be relevant for the formulation of the future-oriented compromise-free process intensification strategies (Pfeuffer and Scherb, 2016). The top 10 SRs with highest contradiction index are shown in Figure 7. Interestingly that the requirements with higher ranking have also a high contradiction index, such as for example N25 "Reduce energy consumption" and N27 "Reduce water consumption". High values of the contradiction index figure out that the fulfilment of the requirements N25 and N27 may worsen the satisfaction with other SRs in a manufacturing process.

\begin{tabular}{|c|c|c|}
\hline Top 10 SRs with high contradiction index & $\begin{array}{c}\text { Top } 10 \text { environmental SRs with high } \\
\text { contradiction index }\end{array}$ & $\begin{array}{c}\text { Top } 10 \text { technological SRs with high } \\
\text { contradiction index }\end{array}$ \\
\hline 25. Reduce energy consumption 15 & 25. Reduce energy consumption 15 & 18. Reduce granulation time \\
\hline 27. Reduce water consumption 14 & 27. Reduce water consumption 14 & 13. Avoid temperature range... \\
\hline 18. Reduce granulation time 13 & 26. Reduce cleaning efforts $\boldsymbol{\square}$ & 14. Reduce non-homogenized wet. \\
\hline 13. Avoid temperature range.. 10 & 24. Reduce dust generation $\mathbf{D}$ & 16. Avoid over and underload in.. 7 \\
\hline 14. Reduce non-homogenized wet. 8 & 11. Control speed of sieving machine $=4$ & 12. Reduce non-homogenized.. 6 \\
\hline 26. Reduce cleaning efforts $=7$ & 20. Reduce noise level in drying... 1 & 28. Avoid sticky granulate 6 \\
\hline 16. Avoid over and underload in.. 7 & 6. Avoid high pressure in weighing... 0 & 30. Avoid friable tablets $=5$ \\
\hline 12. Reduce non-homogenized.. 6 & 4. Decrease safety risks in warehouse 0 & 31. Avoid poor tablet pressing $=5$ \\
\hline 28. Avoid sticky granulate $=6$ & 23. Minimize energy losses in... 0 & 15. Reduce formation of lumps,... 5 \\
\hline 24. Reduce dust generation $\mathbf{a}$ & 21. Minimize air pollution in drying... 0 & 10. Reduce uneven particle size... 4 \\
\hline
\end{tabular}

Figure 7. Top 10 stakeholder requirements with high contradiction index

Combing of both metrics - the ranking and the contradiction index of requirements, allows one to reorder the top 10 SRs to the top 10 high ranking requirements with highest contradiction index, as illustrated in Figure 8. Remarkably, that the environmental stakeholder requirements N25 "Reduce energy consumption", N27 "Reduce water consumption" and N26 "Reduce cleaning efforts" appear now in the three top positions among all SRs. On the other hand, the requirements with high contradiction index N27 "Reduce granulation time" and N28 "Avoid sticky granulate" belong to the most critical technological SRs. Finally, a comparison of SRs in Figures 6 and 7 shows that energy and water consumption, granulation time and cleaning efforts belong to the most critical innovation criteria. 


\begin{tabular}{|c|c|c|c|c|c|}
\hline \multicolumn{2}{|c|}{$\begin{array}{l}\text { Top } 10 \text { high ranking SRs with } \\
\text { highest contradiction index }\end{array}$} & \multicolumn{2}{|c|}{$\begin{array}{l}\text { Top } 10 \text { high ranking environmental SRs with } \\
\text { highest contradiction index }\end{array}$} & \multicolumn{2}{|c|}{$\begin{array}{c}\text { Top } 10 \text { high ranking technological SRs with } \\
\text { highest contradiction index }\end{array}$} \\
\hline 25. Reduce energy consumption & = 15 & 25. Reduce energy consumption & = 15 & 18. Reduce granulation time & 13 \\
\hline 27. Reduce water consumption & 14 & 27. Reduce water consumption & 14 & 28. Avoid sticky granulate & \\
\hline 26. Reduce cleaning efforts & 7 & 26. Reduce cleaning efforts & $=7$ & 30. Avoid friable tablets & - 5 \\
\hline 28. Avoid sticky granulate & 6 & 24. Reduce dust generation & - 5 & 31. Avoid poor tablet pressing & - 5 \\
\hline 24. Reduce dust generation & - 5 & 11. Control speed of sieving machine & = 4 & 29. Avoid non homogenized. . & - 4 \\
\hline 29. Avoid non homogenize blending... & - 4 & 20. Reduce noise level in dryer 1 & 11 & 22. Reduce membrane fouling in... & 1 \\
\hline 22. Reduce membrane fouling in... & 1 & 23. Minimize energy losses in drying & 0 & 2. Control raw material quality & 0 \\
\hline 20. Reduce noise level in dryer & 1 & 21. Minimize air pollution in drying & 0 & 8. Avoid weighing errors of.. & 0 \\
\hline 23. Minimize energy losses in drying & 0 & 6. Avoid high pressure in weighing... & 0 & 9. Avoid cross contamination of raw.. & 0 \\
\hline 21. Minimize air pollution in drying & 0 & 4. Decrease safety risks in warehouse & 0 & 5. Avoid material labelling mistakes & 0 \\
\hline
\end{tabular}

Figure 8. Top 10 high ranking stakeholder requirements with highest contradiction index

\subsubsection{Technical requirements with high total relevance}

The technical requirements TRs with high total relevance objectively point out the process steps and equipment critical to the stakeholder requirements with higher ranking. As presented in Table 2, the technical function of the drying unit N14 "Dries wet granulates to less than 2\% of moisture content" has the highest total relevance of $29,3 \%$ among all 19 technical requirements, followed by technical function of the kneader N12 "Mills and homogenizes materials and solution" in the granulation process with the relevance of $22.2 \%$, and by the pre-blender function N10 "Pre-blends materials for homogenization".

Table 2. Top 10 technical requirements with high total relevance

\begin{tabular}{|c|c|c|c|c|}
\hline Process step & Equipment & Technical function & $\begin{array}{c}\text { Total } \\
\text { Relevance }\end{array}$ & $\begin{array}{l}\text { Type of } \\
\text { function }\end{array}$ \\
\hline 4. Drying & 4.1 Dryer & 14) Dries wet granules & $29.3 \%$ & $\mathrm{~T}$ \\
\hline 3. Granulation & 3.1 Kneader & $\begin{array}{l}\text { 12) Mills and homogenizes materials and } \\
\text { solution }\end{array}$ & $22.2 \%$ & $\mathrm{~T}$ \\
\hline 2. Pre-milling & 2.1 Pre-blender & 10) Pre-blends materials for homogenisation & $21.9 \%$ & $\mathrm{~T}$ \\
\hline $\begin{array}{l}\text { 1. Raw } \\
\text { material } \\
\text { preparation }\end{array}$ & $\begin{array}{l}1.4 \text { Sieve and belt } \\
\text { conveyers }\end{array}$ & 6) Sieve materials particle size to $0.5 \mathrm{~mm}$ & $19.3 \%$ & $\mathrm{~T}$ \\
\hline 4. Drying & 4.2 Sieve & $\begin{array}{l}\text { 15) Sieves dried granules for uniform } \\
\text { particle distribution }\end{array}$ & $17.5 \%$ & $\mathrm{~T}$ \\
\hline \multirow{3}{*}{$\begin{array}{l}\text { 1. Raw } \\
\text { material } \\
\text { preparation }\end{array}$} & $\begin{array}{l}1.4 \text { Sieve and belt } \\
\text { conveyers }\end{array}$ & $\begin{array}{l}\text { 7) Separate unwanted materials (plastic and } \\
\text { metal) }\end{array}$ & $16.4 \%$ & $\mathrm{~T}$ \\
\hline & \multirow{2}{*}{$\begin{array}{l}\text { 1.1. Excavator } \\
\text { and belt } \\
\text { conveyers }\end{array}$} & $\begin{array}{l}\text { 1) Transport raw material from reception to } \\
\text { bins }\end{array}$ & $15.5 \%$ & $\mathrm{~T}$ \\
\hline & & $\begin{array}{l}\text { 2) Convey raw material from bins to } \\
\text { containers }\end{array}$ & $15.5 \%$ & $\mathrm{~T}$ \\
\hline 2. Pre-milling & $\begin{array}{l}2.2 \text { Dissolution } \\
\text { mixer }\end{array}$ & 11) Dissolves binding agent with pure water & $14.9 \%$ & $\mathrm{~T}$ \\
\hline 4. Drying & 4.3 Mixer & $\begin{array}{l}\text { 16) Mixes dried granules with other } \\
\text { excipients }\end{array}$ & $14.5 \%$ & $\mathrm{~T}$ \\
\hline
\end{tabular}

\subsubsection{Technical requirements with high contradiction index}

Table 3 presents technical requirements TRs with the highest contradiction index. Among 19 technical requirements to the existing equipment for tablet production, the technical functions N18 "Removes dust from the facilities" and N19 "Separates and recycles mud from water" have the highest contradiction index. Many processes in pharmaceutical manufacturing generate dust over the equipment. In order to keep the sterile environment and avoids contamination of materials, the dust collection system has a significant workload, and requires additionally high cleaning efforts, which consequently increase water consumption. Interestingly, that the auxiliary function of dust removal, 
doesn't appear in the list of technical requirements with high relevance in Table 2. Apparently, using only one metric for selection of technical functions and corresponding equipment for further process intensification is not sufficient for a reliable and comprehensive choice of innovation tasks.

Table 3. Top 10 technical requirements with high contradiction index

\begin{tabular}{|c|c|c|c|c|}
\hline Process & Equipment & Technical function & $\begin{array}{l}\text { Contradiction } \\
\text { Index }\end{array}$ & $\begin{array}{l}\text { Type of } \\
\text { function }\end{array}$ \\
\hline \multirow[b]{2}{*}{ 6. Utility } & 6.1 Dust collector & 18) Removes dust from the facilities & 14 & $\mathrm{E}$ \\
\hline & $\begin{array}{l}6.2 \text { Water depuration } \\
\text { system }\end{array}$ & $\begin{array}{l}\text { 19) Separates and recycles mud from } \\
\text { water }\end{array}$ & 3 & $\mathrm{E}$ \\
\hline \multirow{2}{*}{ 2. Pre-milling } & 2.1 Pre-blender & $\begin{array}{l}\text { 10) Pre-blends materials for } \\
\text { homogenisation }\end{array}$ & 2 & $\mathrm{~T}$ \\
\hline & $\begin{array}{l}2.2 \text { Dissolution } \\
\text { mixer }\end{array}$ & $\begin{array}{l}\text { 11) Dissolves binding agent with pure } \\
\text { water }\end{array}$ & 2 & $\mathrm{~T}$ \\
\hline 3. Granulation & 3.1 Kneader & $\begin{array}{l}\text { 12) Mills and homogenizes materials } \\
\text { and solution }\end{array}$ & 2 & $\mathrm{~T}$ \\
\hline 4. Drying & 4.1 Dryer & $\begin{array}{l}\text { 14) Dries wet granules to }<2 \% \text { of } \\
\text { moisture content }\end{array}$ & 2 & $\mathrm{~T}$ \\
\hline \multirow{4}{*}{$\begin{array}{l}\text { 1. Raw material } \\
\text { preparation }\end{array}$} & \multirow{2}{*}{$\begin{array}{l}\text { 1.1 Excavators and } \\
\text { belt conveyers }\end{array}$} & $\begin{array}{l}\text { 1) Transport raw material from } \\
\text { reception to bins }\end{array}$ & 1 & $\mathrm{~T}$ \\
\hline & & $\begin{array}{l}\text { 2) Convey raw material from bins to } \\
\text { containers }\end{array}$ & 1 & $\mathrm{~T}$ \\
\hline & \multirow{2}{*}{ 1.2 Containers } & 3) Store raw material & 1 & $\mathrm{~T}$ \\
\hline & & 4) Maintain quality of raw material & 1 & $\mathrm{~T}$ \\
\hline
\end{tabular}

\subsubsection{Selection of the top 5 innovation design tasks for process intensification}

Figure 9 presents the top five stakeholder requirements SRs and top 5 technical requirements TRs for process intensification, which were identified by the analysis and combination of various metrics presented in the sub-sections 4.1.1 to 4.1.5 above. The requirements from various top 10 lists with highest frequency of mentioning can be recommended for innovation tasks. In case of SRs, the requirements with high importance, ranking and contradiction index have been taken into consideration. The selection criteria of the equipment to be improved were the technical requirements with highest total relevance and highest contradiction index.

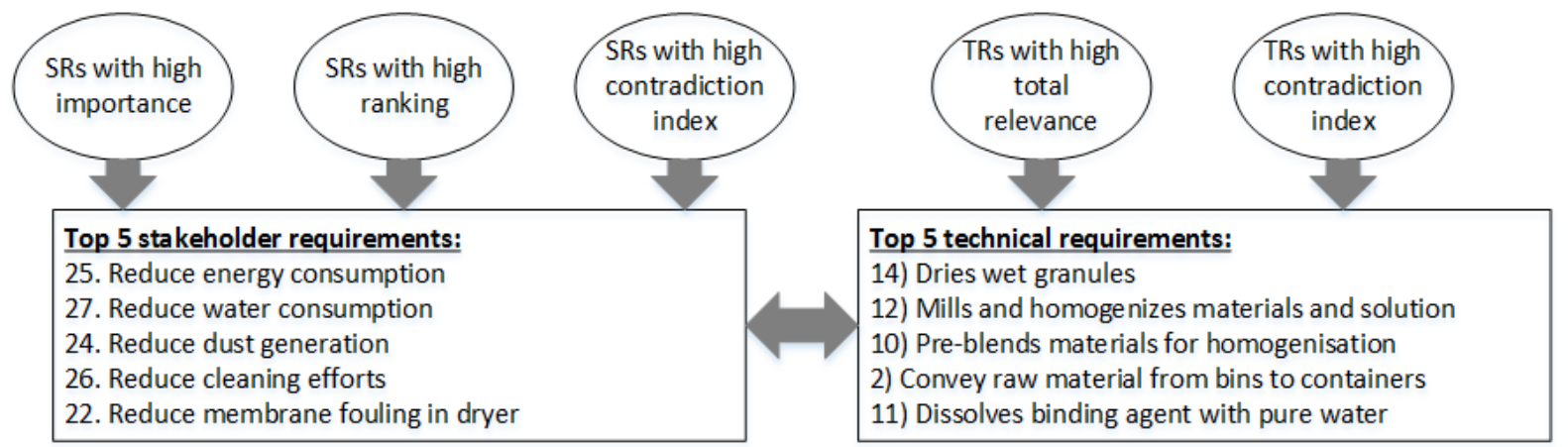

Figure 9. Innovation design tasks for process intensification of pharmaceutical processes

Alternatively, the selection of requirements for the innovation strategy in process intensification can be performed by a pick SRs and TRs with highest values of the metrics presented in the sub-sections 4.1.1-4.1.5: N25, N27, N18, N26, N28 - for stakeholder requirements, and N14, N12, N10, N6, N18 for technical requirements. The identified innovation design tasks presented in Figure 9 confirm that each stakeholder requirement has its 3 to 5 corresponding technical requirements of equipment, marked with "YES" in the body of House of Quality in Figure 10. 


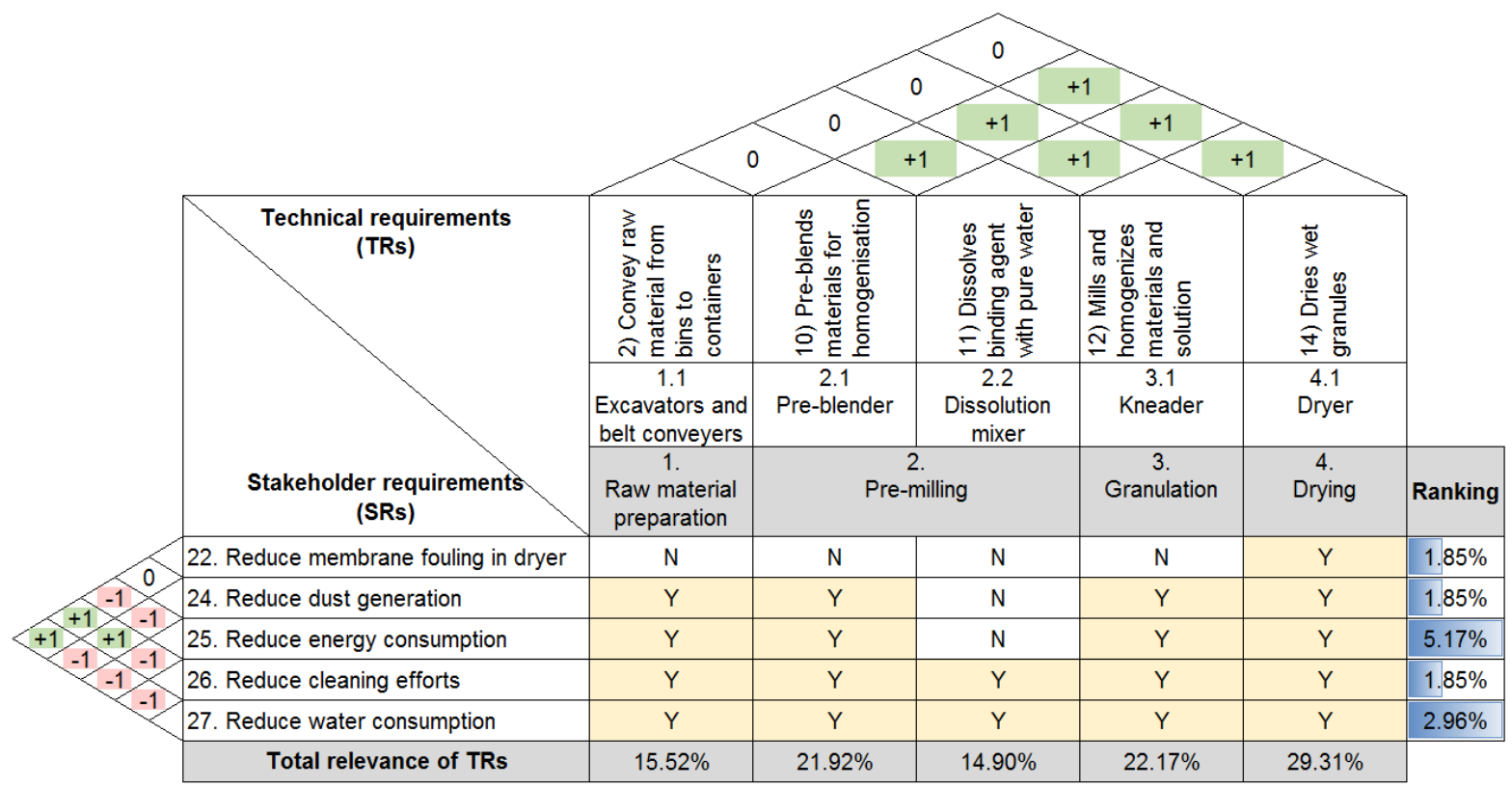

Figure 10. Cross-relationship of innovation tasks between selected SRs and TRs

\subsection{Potential secondary impact of innovation tasks}

The positive and negative correlations between the selected stakeholder requirements, presented in Figure 10 allows one to easily and practically automatically capture a potential secondary impact of each innovation task. For instance, as illustrated in Figure 11, the reduction of the water consumption (SR N27) will support the reduction of the membrane fouling (SR N22) but possibly change to worse the satisfaction with the requirements SR N24, SR N25 and SR N26. On the other hand, a successful fulfilment of the SR N27 "Reduce water consumption" needs the improvement of the technical functions (TRs) of the following equipment: TR N2, TR N10, TR N11, TR N12, TR N14. Thus, if the process intensification will only focus on the task N27 "Reduce water consumption" in dryer (technical requirement N14), there are three potential secondary innovation tasks to be considered additionally:

reduce energy consumption in dryer (SR N27)

- without causing dust generation in dryer (SR N24),

- without higher energy consumption in dryer (SR N25),

- without additional cleaning efforts of dryer (SR N26).

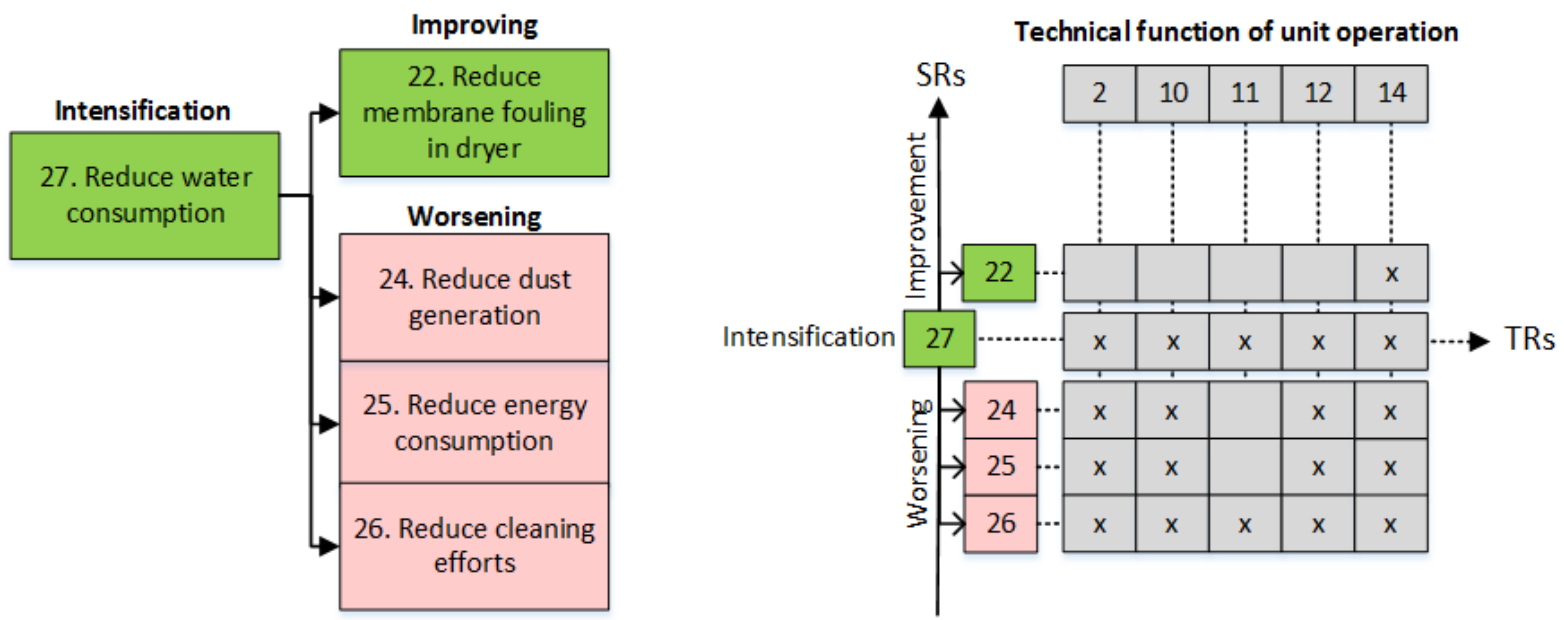

Figure 11. Example of the cause-effect chain analysis for the stakeholder requirement N27 "Reduce water consumption" 


\section{Conclusion and outlook}

Identification and selection of the innovation design tasks for process intensification comprise a series of judgements concerning various requirements and metrics. Combining the Quality Function Deployment approach and Importance-Satisfaction Analysis (ISA), the proposed method helps to increase the reliability of the innovation task definition, as the selection of the tasks is based on a multi-criteria approach. The method considers the stakeholder requirements with high importance, high ranking, and with high contradiction index, and additionally the technical requirements or functions with high total relevance for stakeholder requirements and high contradiction index. The synergy indexes of selected requirements and the preventive analysis of potential secondary impact can be also taken into account while comparing different innovation scenarios. The proposed method presents a systematic way to document comprehensively the initial problem situation, and to reliably identify the innovation tasks for process intensification based on individual judgements of stakeholders. It also helps engineers to recognise possible cause-effect chains within a selected package of tasks. However, the method does not allow to measure and to compare the cause-effect impact in numbers. Therefore, the accountable cause-effect analysis could be a part of future work.

\section{References}

Akao, Y. (1986), Quality Function Deployment, Productivity Press, Cambridge.

Azzaro-Pantel, C. (2015), "Green Process Engineering Design Methodology: A Multicriteria Approach", In: Poux, M., Cognet, P. and Gourdon, C. (Eds.), Green Process Engineering: From Concepts to Industrial Applications, CRC Press, Boca Raton, pp. 3-26. ISBN 9781482208177.

Bettencourt, L. and Ulwick, A. (2008), "The customer-centered innovation map", Harvard Business Review, Vol. 86 No. 5, pp. 109-114.

Boodhoo, K. and Harvey, A. (2013), "Process Intensification: An overview of principles and practice", In: Boodhoo, K. and Harvey, A. (Eds.), Process Intensification for Green Chemistry, John Wiley \& sons, pp. 1-31. https://doi.org/10.1002/9781118498521.ch1

Casner, D. and Livotov, P. (2017), "Advanced innovation design approach for process engineering", Proceedings of the 21st International Conference on Engineering Design (ICED 2017), Vol. 4: Design Methods and Tools, Vancouver, pp. 653-662.

Chan, L.K. and Wu, M.L. (2002), "Quality function deployment: a literature review", Eur. J. Oper. Res, Vol. 143 , pp. 463-497.

Dobrusskin, C. (2016), "On the Identification of Contradictions Using Cause Effect Chain Analysis", Procedia CIRP, Vol. 39, TFC 2015, pp. 221-224. https://doi.org/10.1016/j.procir.2016.01.192

Livotov, P. (2008), "Method for quantitative evaluation of innovation tasks for technical systems, products and processes", Proceedings of ETRIA World Conference, 2008, Synthesis in Innovation, Enschede, 5-7 November 2008, pp. 197-199. University of Twente, Enschede (2008). ISBN 978-90-365-2749-1

Mas'udah Livotov, P. and Chandra Sekaran, A.P. (2019), "Sustainable Innovation in Process Engineering Using Quality Function Deployment Approach and Importance-Satisfaction Analysis of Requirements", In: Benmoussa, R., De Guio, R., Dubois, S. and Koziołek, S. (Eds.), New Opportunities for Innovation Breakthroughs for Developing Countries and Emerging Economies, Springer, Cham, pp. 269-281. https://doi.org/10.1007/978-3-030-32497-1_22, 12

Masui, K. (2001), "Quality function deployment for environment: QFDE - a methodology in early stage of DfE", Proceedings of Second International Symposium on Environmentally Conscious Design and Inverse Manufacturing, Japan, IEEE, pp. 852-857. https://doi.org/10.1109/ECODIM.2001.992480

Pfeuffer, V. and Scherb, B. (2016), "Identification of New Business Fields and Development Directions Using Contradictions", Procedia CIRP, Vol. 39, pp. 197-202. https://doi.org/10.1016/j.procir.2016.01.188

Sisasamy, K., Arumugan, C. and Devadasan, S.R. (2016), "Advanced models of quality function deployment: a literature review", Qual. Quant, Vol. 50, pp. 1399-1414. https://doi.org/10.1007/s11135-015-0212-2

Tyl, B. et al. (2016), "A comparative study of ideation mechanisms used in eco-innovation tools", Journal of Engineering Design, Vol. 25 No. 10-12, pp. 325-345. https://doi.org/10.1080/09544828.2014.992772 